\title{
STATIC AND DYNAMIC ANALYSIS OF SHELLS OF REVOLUTION USING THE COLLOCATION METHOD IN SPACE DOMAIN
}

$$
\begin{aligned}
& \text { 三上隆* } \\
& \text { By Takashi MIKAMI }
\end{aligned}
$$

\section{1.はじめに}

款構造は，そのすぐれた力学特性ゆえに建築・土木構 造など多くの分野で広く用いられている.

さて, 静的および動的問題解析の第一歩は, 何らかの 手法により空間領域を離散化することである.離散化手

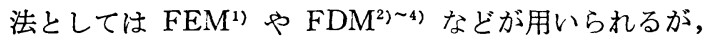
その結果得られる連立方程式および時間に関する連立常 微分方程式の係数行列は大次元となるのが一般的であ る.したがって, 時間依存の問題では, 大次元な係数行 列の固有值が広い範囲に分布し，これに起因して時間領 域の積分が不安定となり解が発散したり, 安定に解くた めには計算時間が長くなるなどの問題点も生ずる. な お，FEM では計算時間の短縮を計るため自由度の低減 がなされるが, 自由度の低減は直接, 精度に関係するの で十分な注意が必要である，さらに，対象とする荷重状 態（たとえば, 風荷重を受ける片持形式の殼）によって は, 曲げモーメント, せん断力などの断面力諸量をたわ みと同程度の 精度で求めることが困難になる 場合もあ り, FEM では高精度の要素の開発を目指し, 研究が続 けられている.

選点法は定式化が容易，選点の選択によっては末知数 の減少などの特性があり, 空間領域の離散化手法として 有望と思われるが，殼に対する適用例は少ない5).

選点法と類似の概念に基づいた手法注 1) (Partition 法， Subdomain Collocation 法とよばれる) が，回転款の固

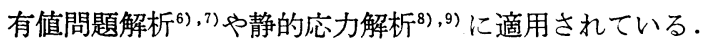
しかし，この手法は領域分割の仕方に大きく依存するも ので, 場の大域的性質で規定される固有値問題を除き, 局所的な応力・変形挙動の把握を必要とする問題への適

* 正会員 工修 北海道大学助手 工学部土木工学科

注 1) ある特定の領域で 1, それ以外ではどこでも零である ような重み関数を考え，定式化する方法.
用は得策とは思えない，また，考察している系を支配す る係数行列の導出過程では, 積分を実行しなければなら ず，特に系が変数係数の微分方程式で与えられる場合に は, 煩雑さは免れない。

本研究は，回転款の静的・動的問題を対象とし，空間 領域に対する選点法の適用性を検討したものである．問 題の定式化の基本的な流れは，4階の支配方程式に基つ く前論文 ${ }^{5)}$ を踏襲するが，ここでは，仮定した試行関数 の高階微分の影響が特に曲げモーメント, せん断力など に現われることを考慮し，微分階数を 2 階に下げた支配 方程式の採用および款の経線方向に沿う要素 (領域) 分 割により, 解の精度向上を計った. また, 選点法のもっ ている定式過程の簡明さが，要素分割によって失われな いように留意し, 考察している系の係数行列がシステマ チックに得られるよう配慮した.

数值計算例では円筒殼, 球殼を取り上げ，手法の妥当 性や適用性の検証を行う。さらに, 空間領域離散化の近 似度の判定に，平均二乗残差を解析に併用すれば，本計 算值はより高精度なものとなることを明らかにする。 な お, 動的応答問題での時間領域の積分には, 直接積分法 を用いた。

\section{2. 回転殼の基礎方程式}

回転殼の 運動方程式は, 円周方向 Fourier 級数展開 により経線方向座標と時間に関する偏微分方程式として 得られる. 以下に Novozhilov の線形壳理論 ${ }^{10}$ に基つきき， 基礎方程式を導く過程を略述する. その際，曲げモーメ ント，せん断力などへの 数值的誤差の介入を避けるた め, 変位成分とともに経線方向曲げモーメントを独立な 未知量として扱い，微分方程式の階数低下を計った。 な お，款は等方等質な一様な厚さとした。

Fig. 1 に示す座標系において, $x$ 軸方向 (経線方向), $\theta$ 軸方向 (円周方向), $z$ 軸方向（法線方向，内向きを 


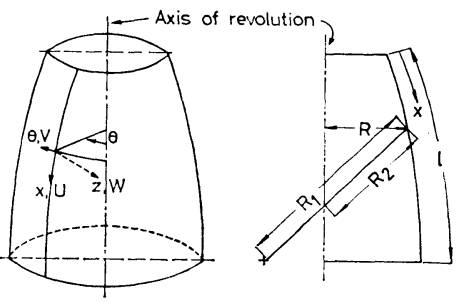

Fig. 1 Typical shell of revolution.

正）の変位をそれぞれ $U, V, W$ で表わす。 また，荷 重成分, 合态力成分および合モーメント成分を, それぞ れ $\left(P_{x}, P_{\theta}, P_{z}\right),\left(N_{x}, N_{\theta}, N_{x \theta}, Q_{x}, Q_{\theta}\right)$ および $\left(M_{x}\right.$, $\left.M_{\theta}, M_{x \theta}\right)$ で表示する. 款の半径を $R$, 主曲率半径を $R_{1}, R_{2}$ および代表長さを $a$ とし, 殸の中央面の形を $R$ $=R(x)$ で与えると, 無次元曲率 $r_{1}\left(=a / R_{1}\right), r_{2}(=a /$ $\left.R_{2}\right)$ および無次元半径 $r(=R / a)$ の間の関係式は

$$
\left.\begin{array}{l}
r_{1} r_{2}=-\left(d r / d \xi+r^{2}\right) / s^{2} \\
d r_{2} / d \xi=r\left(r_{1}-r_{2}\right) \\
r_{2}=\sqrt{1-\left(d^{2} r / d \xi^{2}\right) / s^{2}} / r \\
r_{1} r_{2}=-\left(d^{2} r / d \xi^{2}\right) / r s^{2}
\end{array}\right\}
$$

となる. ここに, $r=(d r / d \xi) / r, \xi=x / l$ および $s=l / a$ であり, l は経線の長さである.

さて，款の運動方程式は次のように与えられる.

$$
\begin{gathered}
\left(r N_{x}\right)^{\prime}+s N_{x \theta}{ }^{*}-N_{\theta}(d r / d \xi)-r r_{1} s Q_{x} \\
\quad+\operatorname{ars}\left(P_{x}-\rho h \partial^{2} U / \partial t^{2}\right)=0 \cdots \cdots \cdots(2 \cdot \mathrm{a}) \\
s N_{\theta}{ }^{*}+\left(r N_{x \theta}\right)^{\prime}+N_{x \theta}(d r / d \xi)-r r_{2} s Q_{\theta} \\
\quad+\operatorname{ars}\left(P_{\theta}-\rho h \partial^{2} V / \partial t^{2}\right)=0 \cdots \cdots \cdots \cdots(2 \cdot \mathrm{b}) \\
s r\left(r_{1} N_{x}+r_{2} N_{\theta}\right)+s Q_{\theta}{ }^{*}+\left(r Q_{x}\right)^{\prime} \\
\quad+\operatorname{ars}\left(P_{z}-\rho h \partial^{2} W / \partial t^{2}\right)=0 \cdots \cdots(2 \cdot \mathrm{c})
\end{gathered}
$$

ここに, ( ) $)^{\prime}=\partial() / \partial \xi,()^{*}=\partial() / \partial \theta$ であり, $\rho, h$ および $t$ は, それぞれ単位体積当たりの質量, 厚さおよ び時間を表わす。また， $Q_{x}$ と $Q_{\theta}$ は次式で与えられ る.

$$
\left.\begin{array}{l}
a Q_{x}=\left\{\left(r M_{x}\right)^{\prime} / s+M_{x \theta}{ }^{*}-M_{\theta}(d r / d \xi) / s\right\} / r \\
a Q_{\theta}=\left\{M_{\theta}^{*}+\left(r M_{x \theta}\right)^{\prime} / s+M_{x \theta}(d r / d \xi) / s\right\} / r
\end{array}\right\}
$$

ひずみおよび曲率と変位の関倸は次のようである.

$$
\left.\begin{array}{rl}
a \varepsilon_{x}=U^{\prime} / s-r_{1} W, & a \varepsilon_{\theta}=V^{*} / r-r_{2} W+r U / s \\
a \varepsilon_{x \theta}= & V^{\prime} / s+U^{*} / r-\gamma V / s, a \chi_{x}=\Phi_{x^{\prime}} / s \\
a \chi_{\theta}=\Phi_{\theta}^{*} / r+r \Phi_{x} / s, \\
a^{2} \chi_{x \theta}=\left(s r_{1} U^{*} / r+r_{2} V^{\prime}-r r_{2} V+W^{\prime *} / r\right. \\
\left.\quad-r W^{*} / r\right) / s
\end{array}\right\}
$$

ここに， $\Phi_{x}$ および $\Phi_{\theta}$ は，それぞれ 次式で定義される $x$ および $\theta$ 方向の回転角である.

$$
\left.\begin{array}{l}
a \Phi_{x}=W^{\prime} / s+r_{1} U \\
a \Phi_{\theta}=W^{*} / r+r_{2} V
\end{array}\right\}
$$

合応力と合モーメントは次のように与えられる.

$$
\left.\begin{array}{l}
N_{x}=K\left(\varepsilon_{x}+\nu \varepsilon_{\theta}\right), N_{\theta}=K\left(\nu \varepsilon_{x}+\varepsilon_{\theta}\right) \\
N_{x \theta}=(1-\nu) K \varepsilon_{x \theta} / 2, M_{x}=-D\left(\chi_{x}+\nu \chi_{\theta}\right) \\
M_{\theta}=-D\left(\nu \chi_{x}+\chi_{\theta}\right), M_{x \theta}=-(1-\nu) D \chi_{x \theta} / 2
\end{array}\right\}
$$

ここに, $K=E h /\left(1-\nu^{2}\right), D=E h^{3} / 12\left(1-\nu^{2}\right)$ であり, $E$ およびンは，それぞれ弾性係数，ポアソン比である。

さらに, 運動方程式の階数低下を行うための準備とし て, 式 $(6 \cdot \mathrm{d})$ および式 $(6 \cdot \mathrm{e})$ 上り次の式を求めておく.

$$
M_{\theta}=\nu M_{x}-D\left(1-\nu^{2}\right) \chi_{\theta}
$$

変位 $(U, V, W)$, 合応力 $\left(N_{x}, N_{\theta}, N_{x \theta}\right)$, 合モーメ ント $\left(M_{x}, M_{\theta}, M_{x \theta}\right)$ および荷重 $\left(P_{x}, P_{\theta}, P_{z}\right)$ を, それぞれ $(u, v, w),\left(n_{x}, n_{\theta}, n_{x \theta}\right),\left(m_{x}, m_{\theta}, m_{x \theta}\right)$ お よび $\left(p_{x}, p_{\theta}, p_{z}\right)$ を係数とする形で円周方向に Fourier 級数展開する. いま, 代表応力を $\sigma$, 周方向波数を $n$ と記し，一例として正弦展開される量を示すと次のと おりである。

$$
\left\{\begin{array}{c}
V \\
N_{x \theta} \\
M_{x \theta} \\
P_{\theta}
\end{array}\right\}=\sum_{n=0}^{\infty}\left\{\begin{array}{cc}
\left(\sigma a^{2} / E h\right) & v^{(n)} \\
\sigma a & n_{x \theta}^{(n)} \\
\sigma a^{2} & m_{x \theta}(n) \\
\sigma & p_{\theta}^{(n)}
\end{array}\right\} \sin n \theta \cdots(8)
$$

また, 後述する境界条件の規定に必要な諸量を, 同様に Fourier 級数展開しておく.

$$
\left\{\begin{array}{c}
\Phi_{x} \\
S_{x \theta} \\
T_{x}
\end{array}\right\}=\sum_{n=0}^{\infty}\left\{\begin{array}{c}
(\sigma a / E h) \phi_{x}{ }^{(n)} \cos n \theta \\
\sigma a s_{x \theta}{ }^{(n)} \sin n \theta \\
\sigma a t_{x}{ }^{(n)} \cos n \theta
\end{array}\right\}
$$

ここに, $\Phi_{x}$ は式 $(5 \cdot \mathrm{a})$ で与えられ， $S_{x \theta}$ および $T_{x}$ は 次式で定義される等価接線力および等価せん断力であ る.

$$
\left.\begin{array}{l}
S_{x \theta}=N_{x \theta}-r_{2} M_{x \theta} / a \\
T_{x}=\left\{\left(r M_{x}\right)^{\prime} / s+2 M_{x \theta}-M_{\theta}(d r / d \xi) / s\right\} /(r a)
\end{array}\right\}
$$

なお, 以下では Fourier 倸数の添字 $(n)$ は省略する.

以上の諸式を用いれば，回転款の運動方程式は式 $(2$. $\mathrm{a} \sim \mathrm{c})$ および式 (6・d) より， $u, v, w$ および $m_{x}$ に関 する 2 階 4 元連立偏微分方程式として次のように得られ る.

$$
\begin{aligned}
& a_{1} u^{\prime \prime}+a_{2} u^{\prime}+a_{3} u+a_{4} v^{\prime}+a_{5} v+a_{6} w^{\prime}+a_{7} w \\
& +a_{8} m_{x}{ }^{\prime}+a_{9} m_{x}=-p_{x}+\ddot{u} \\
& a_{10} u^{\prime}+a_{11} u+a_{12} v^{\prime \prime}+a_{13} v^{\prime}+a_{14} v+a_{15} w^{\prime \prime} \\
& +a_{16} w^{\prime}+a_{17} w+a_{18} m_{x}=-p_{\theta}+\ddot{v} \\
& a_{19} u^{\prime}+a_{20} u+a_{21} v^{\prime \prime}+a_{22} u^{\prime}+a_{23} v \\
& +a_{24} w^{\prime \prime}+a_{25} w^{\prime}+a_{26} w+a_{27} m_{x}^{\prime \prime} \\
& +a_{28} m_{x}{ }^{\prime}+a_{29} m_{x}=-p_{z}+\ddot{w} \quad \cdots \cdots(11 \cdot \mathrm{c}) \\
& a_{30} u^{\prime}+a_{31} u+a_{32} v+a_{33} w^{\prime \prime}+a_{34} w^{\prime}+a_{35} w \\
& +a_{36} m_{x}=0 \text {. }
\end{aligned}
$$

ここに, ()$^{\bullet}=\partial() / \partial \tau$ であり, $\left.\tau^{\prime}=(E / \rho)^{1 / 2} t / a\right)$ は 
無次元時間である.なお, 係数 $a_{1} \sim a_{36}$ は付録 $\mathrm{I}$ を参照 されたい.

境界条件は, 次の 4 組の対の適当な組合せによって構 成される.

$$
\left.\begin{array}{l}
W \text { or } T_{x}, \Phi_{x} \text { or } M_{x} \\
U \text { or } N_{x}, V \text { or } S_{x \theta}
\end{array}\right\}
$$

ここで, 4. の定式化において必要な $N_{x}, S_{x \theta}, T_{x}$ およ び $\Phi_{x}$ の各 Fourier 係数の内容を以下に示しておく.

$$
\begin{aligned}
n_{x}= & b_{1} u^{\prime}+b_{2} u+b_{3} v+b_{4} w \\
s_{x \theta}= & b_{5} u+b_{6} v^{\prime}+b_{7} v+b_{8} w w^{\prime}+b_{9} w \\
t_{x}= & b_{10} u+b_{11} v^{\prime}+b_{12} v+b_{13} w^{\prime}+b_{14} w \\
& +b_{15} m_{x}+b_{16} m_{x} \\
\phi_{x}= & b_{17} u+b_{18} w^{\prime}
\end{aligned}
$$

$$
\}
$$

$(13 \cdot a \sim d)$

なお，係数 $b_{1} \sim b_{18}$ は付録 I を参照されたい。

\section{3. 選点法の概略 ${ }^{11), 12)}$}

本論文では選点法を, 空間領域の離散化のために用い る.ここでは，その概略を述べ 4. の準備とする.

いま, 時間 $\tau$ および空間 $\xi$ に関する次のような方程 式が与えられたとする.

$$
L u+\ddot{u}=0(0<\xi<1, \tau>0)
$$

ここに，Lは 2 階の線形演算子である.さらに，空間に 対する 2 個の境界条件が与えられていると仮定する.

関数 $u$ を時間と空間の積として次のように近似す る。

$$
u(\xi, \tau)=\sum_{i=1}^{M+2} d_{i-1}(\tau) \xi^{i-1}
$$

ここに, 未定のパラメーターは時間の関数であり, それ らを定める条件は以下のように与えられる.

式（15）を式（14）に代入すると残差 $R$ が生ずる.

$$
R(\xi, \tau)=\sum_{i=1}^{M+2}\left\{d_{i-1}(\tau) L\left(\xi^{i-1}\right)+\ddot{d}_{i-1}(\tau) \xi^{i-1}\right\}
$$

まず $M$ 個の条件は, 空間領域内の $M$ 個の点（選点） で次の条件を課すことにより得られる.すなわち

$$
R\left(\xi_{j}, \tau\right)=0,(j=1 \sim M)
$$

式 (17) は時間に関する $M$ 元常微分方程式を表わし, さらにこれに加えて, 空間に対する境界条件より 2 本の 方程式が得られる.これら $(M+2)$ 本の時間依存の方 程式は, 初期条件を介して解かれ未定係数 $d$ が決定され る.

選点法による解の精度は, 選点の取り方に 左右され る. 今日では, 任意でなく直交多項式の零点を選点とす ることにより解の信頼性が増すことが知られている ${ }^{11)}$. 本論文では, 選点として区間 $[0,1]$ で定義される shifted Legendre 多項式 ${ }^{13)} P_{M} *(\xi)$ の零点 $\xi_{j}(j=1 \sim M)$
を用いる注 2)。

さて, 式 (15) そのものを用いて問題の定式化をすれ ば, 物理的意味をもたない係数 $d$ を求める問題に帰着 するが, 本論文では関数の值, すなわち内部選点と端点 (これについては後述する) の時刻 てにおける值を定め る問題に変換する. まず準備として, 式 (15) のちに 関する 1,2 次微分を求め, 内部選点 $\xi_{j}(j=1 \sim M$, 以 後 $M$ を選点数とよぶ）および端点 $\xi_{0}=0, \xi_{M+1}=1$ で の值を計算する.

$$
\left.\begin{array}{l}
u\left(\xi_{j}\right)_{\tau} \equiv u\left(\xi_{j}, \tau\right)=\sum_{i=1}^{M+2} d_{i-1}(\tau) \xi^{i-1} \\
\left.\frac{\partial u}{\partial \xi}\right|_{\xi_{j}}=\left.\sum_{i=1}^{M+2} \frac{\partial \xi^{i-1}}{\partial \xi}\right|_{\xi_{j}} d_{i-1}(\tau) \\
\left.\frac{\partial^{2} u}{\partial \xi^{2}}\right|_{\xi_{j}}=\left.\sum_{i=1}^{M+2} \frac{\partial^{2} \xi^{i-1}}{\partial \xi^{2}}\right|_{\xi_{j}} d_{i-1}(\tau)
\end{array}\right\}
$$

$(18 \cdot a \sim c)$

ここに, $j=0,1, \cdots, M+1$. 上式を行列表示すると

$$
\left.\begin{array}{l}
\boldsymbol{u}_{\tau}=\boldsymbol{Q} \boldsymbol{d}_{\tau}, \boldsymbol{u}_{\tau}^{\prime}=\boldsymbol{C} \boldsymbol{d}_{\tau} \\
\boldsymbol{u}_{\tau}^{\prime \prime}=\boldsymbol{D} \boldsymbol{d}_{\tau}
\end{array}\right\}
$$

となる.ここに, 添字 ては時間を, プライムはらに関 する微分を表わすものとする. $(M+2) \times 1$ 次のベクト ル $\boldsymbol{d}_{\tau}, \boldsymbol{u}_{\tau}, \boldsymbol{u}_{\tau}^{\prime}$ および $\boldsymbol{u}_{\tau}^{\prime \prime}$ は, 次のように表わされる.

$$
\left.\begin{array}{l}
\boldsymbol{d}_{\tau}{ }^{T}=\left(d_{0}(\tau), d_{1}(\tau), \cdots, d_{M+1}(\tau)\right) \cdots \cdots \cdots(20) \\
\boldsymbol{u}_{\tau}{ }^{T}=\left(u\left(\xi_{0}\right)_{\tau}, u\left(\xi_{1}\right)_{\tau}, \cdots, u\left(\xi_{M+1}\right)_{\tau}\right) \\
\boldsymbol{u}_{\tau}{ }^{T}=\left(u^{\prime}\left(\xi_{0}\right)_{\tau}, u^{\prime}\left(\xi_{1}\right)_{\tau}, \cdots, u^{\prime}\left(\xi_{M+1}\right)_{:}\right) \\
\boldsymbol{u}_{\tau}^{\prime \prime T}=\left(u^{\prime \prime}\left(\xi_{0}\right)_{\tau}, u^{\prime \prime}\left(\xi_{1}\right)_{\tau}, \cdots, u^{\prime \prime}\left(\xi_{M+1}\right)_{\tau}\right)
\end{array}\right\}
$$

さらに, $(\boldsymbol{M}+2) \times(\boldsymbol{M}+2)$ 次の行列 $\boldsymbol{Q}, \boldsymbol{C}, \boldsymbol{D}$ の成分 は,

$$
\left.\begin{array}{l}
Q_{j i}=\xi_{j-1}^{i-1}, C_{j i}=(i-1) \xi_{j-1}^{i-2} \\
D_{j i}=(i-1)(i-2) \xi_{j-1}^{i-3}
\end{array}\right\} \cdots \cdots(22 \cdot \mathrm{a} \sim \mathrm{c})
$$

と表わされる.ここに, $j, i=1,2, \cdots, M+2$.

式（19）より d を消去すれば，時刻 $\tau$ でのるに関 する微分は, 時刻 $\tau$ での内部選点と端点における 関数 值と結びつけられ次式で与えられる.

$$
\boldsymbol{u}_{\tau}{ }^{\prime}=\boldsymbol{A} \boldsymbol{u}_{\tau}, \boldsymbol{u}_{\tau}{ }^{\prime \prime}=B \boldsymbol{u}_{\tau}
$$

ここに, $(M+2) \times(M+2)$ 次の行列 $\boldsymbol{A}$ および $\boldsymbol{B}$ は次 のようになる.

$$
A=C Q^{-1}, B=D Q^{-1}
$$

なお, 今後は簡単のために添字ては省略され, 式 (21) のベクトルは内部選点と端点に分離され次の上うに記さ れる.たとえば, $\boldsymbol{u}$ については次式となる.

$$
\left.\begin{array}{l}
\boldsymbol{u}_{c}{ }^{T}=\left(u\left(\xi_{1}\right), u\left(\xi_{2}\right), \cdots, u\left(\xi_{M}\right)\right) \\
\boldsymbol{u}_{e}{ }^{T}=\left(u\left(\xi_{0}\right), u\left(\xi_{M+1}\right)\right)
\end{array}\right\} \cdots(25 \cdot \mathrm{a}, \mathrm{b})
$$

ここに, 添字 $c$ は内部選点を, 添字 $e$ は端点を表わす

注 2) $P_{M}{ }^{*}(\xi)$ と Legendre 多項式 $P_{M}(X)$ おょびそれら の多項式の零点の関係は次のようである.

$P_{.}{ }^{*}(\xi)=P_{M}(1-2 \xi), \xi_{j}=\left(1+X_{j}\right) / 2 \quad(j=1 \sim M)$. 
ものとする.

次章では, 先の行列 $\boldsymbol{A}$ および $\boldsymbol{B}$ を用い下回転殼の 空間領域の離散化を試みる.

\section{4. 回転殼の空間領域の離散化}

Fig. 2 に示すように，回転殸を回転軸に沿って $N$ 個 の要素に分割する. $k$ 番目の要素を $(k)$ 要素と名付け,

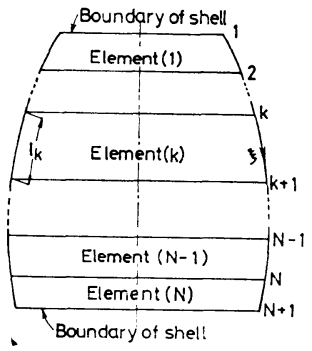

Fig. 2 Division of shell into $N$ elements. 境界条件が指定される点を $1, N+1$, 分割点を $2,3, \cdots$, $N$ と番号付けをする. 各要 素の経線の長さを $l_{k}(k=1 \sim$ $N)$ と表わし, 要素は $0 \leq \xi$ $\leq 1$ の領域で定義されると する.

いま, (k) 要素に着目し， 先に述べたように未知関数 $u^{(k)}, v^{(k)}, w^{(k)}$ および $m_{x}^{(k)}$ (以下，(k) 要素汇関する諸 量は肩添字 (k) を付して表わす)を, 式 (15) の形で表 わす.このとき時間に関する未知係数の数は，1個の要 素では $4(M+2), N$ 個の要素では $4(M+2) N$ となる. また, 内部選点と端点における関数の 1,2 次微分の值 は，式 (23) の形で与えられる.たとえば $w^{(k)}$ は，

$$
\boldsymbol{w}^{\prime(k)}=\boldsymbol{A} \boldsymbol{w}^{(k)}, \boldsymbol{w}^{\prime \prime(k)}=\boldsymbol{B} \boldsymbol{w}^{(k)} \ldots \ldots \ldots(26 \cdot \mathrm{a}, \mathrm{b})
$$

となる.ここに，行列 $\boldsymbol{A}$ および $\boldsymbol{B}$ は式 (24) で与え られ, ベクトル $\boldsymbol{w}^{(k)}$ などは式 (21) に類似な形で表わ される。

さて，4(M+2)N 個の条件は, 次の (1)，(2) 敌よび (3) で与えられる.

\section{（1） $4 M N$ 個の条件}

$4 M N$ 個の条件は, 基礎微分方程式の内部選点におけ る残差の条件を求めることによって定放れる.

いま，(k) 要素について考えてみる.（k）要素の未知 関数を式 (11) に代入すれば, 残差 $R_{i}{ }^{(k)}(\xi, \tau)$ (i=1〜 4 であり，式（11・a〜d）に対応する）が生ずる. した がって, まず $4 M$ 個の条件は, Diracのデル夕関数を 用いれば,

$$
\int_{0}^{1} R_{i}{ }^{(k)}(\xi, \tau) \delta\left(\xi-\xi_{j}\right) d \xi=R_{i}{ }^{(k)}\left(\tilde{\zeta}_{j}, \tau\right)=0
$$

と表現される. ここに, $i=1 \sim 4, j=1 \sim M$.

上式の $i=1$ に対する具体形を, 式 (11·a) に現われ る微分の階数に留意し, 式 (24) の行列 $\boldsymbol{A}$ と $\boldsymbol{B}$ を用い て示すと，

$$
\sum_{j=1}^{M+2}\left[\left\{a_{1}{ }^{(k)}\left(\xi_{i}\right) B_{i+1}, j+a_{2}{ }^{(k)}\left(\xi_{i}\right) A_{i+1, j}\right.\right.
$$

$$
\begin{aligned}
& \left.+a_{3}{ }^{(k)}\left(\xi_{i}\right) \delta_{i+1}, j\right\} u^{(k)}\left(\xi_{j-1}\right) \\
& +\left\{a_{4}{ }^{(k)}\left(\xi_{i}\right) A_{i+1}, j+a_{5}{ }^{(k)}\left(\xi_{i}\right) \delta_{i+1, j}\right\} v^{(k)}\left(\xi_{j-1}\right) \\
& +\left\{a_{6}{ }^{(k)}\left(\xi_{i}\right) A_{i+1, j}+a_{7}{ }^{(k)}\left(\xi_{i}\right) \delta_{i+1}, j\right\} w^{(k)}\left(\xi_{j-1}\right) \\
& \left.+\left\{a_{8}{ }^{(k)}\left(\xi_{j}\right) A_{i+1, j}+a_{9}{ }^{(k)}\left(\xi_{j}\right) \delta_{i+1}, j\right\} m_{x}{ }^{(k)}\left(\xi_{j-1}\right)\right] \\
& =-p_{x}{ }^{(k)}\left(\xi_{i}\right)+\ddot{u}^{(k)}\left(\xi_{i}\right) \quad(i=1 \sim M) \quad \cdots \cdots(28)
\end{aligned}
$$

となる. ここに, $\delta_{i+1, j}(i+1=j$ のとき $1, i+1 \neq j$ のとき0) は Kronecker のデルタ記号であり, $A_{i+1, j}$ および $B_{\boldsymbol{i}+1, j}$ はそれぞれ, 行列 $\boldsymbol{A}$ および $\boldsymbol{B}$ の成分を 表わす。

同様に式 (27) の他の場合も, 式 (28) に類似な形で 表わされ, 最終的に $(k)$ 要素から得られる $4 M$ 個の条 件は, 時間に関するマトリックス常微分方程式の系で,

$$
\boldsymbol{\alpha}_{c}{ }^{(k)} \boldsymbol{\delta}_{c}{ }^{(k)}+\boldsymbol{\alpha}_{e}{ }^{(k)} \boldsymbol{\partial}_{e}{ }^{(k)}=\boldsymbol{p}_{c}{ }^{(k)}+\boldsymbol{\beta}_{c}{ }^{(k)} \ddot{\boldsymbol{\delta}}_{c}^{(k)}
$$

と得られる.ここに, 添字 $c, e$ はそれぞれ内部選点, 端点に関する行列, ベクトルを表わす. ベクトルの具体 的な内容を式 (25) の表わし方に従って示すと

$$
\begin{aligned}
& \boldsymbol{\delta}_{c}{ }^{(k) T}=\left(\boldsymbol{u}_{c}{ }^{(k) T}, \boldsymbol{v}_{c}{ }^{(k) T}, \boldsymbol{w}_{c}{ }^{(k) T}, \boldsymbol{m}_{c}{ }^{(k) T}\right)_{1 \times 4 M} \\
& \boldsymbol{\delta}_{e}^{(k) T}=\left(u_{e}^{(k) T}, v_{e}^{(k) T}, w_{e}^{(k) T}, m_{e}^{(k) T}\right)_{1 \times 8} \\
& \boldsymbol{p}_{c}{ }^{(k) T}=\left(\boldsymbol{p}_{x}{ }^{(k) T}, \boldsymbol{p}_{\theta}{ }^{(k) T}, \boldsymbol{p}_{z}{ }^{(k) T}, 0\right)_{1 \times 4 M} \\
& \ddot{\boldsymbol{\delta}}_{c}^{(k) T}=\left(\ddot{\boldsymbol{u}}_{c}{ }^{(k) T}, \ddot{\boldsymbol{v}}_{c}^{(k) T}, \ddot{\boldsymbol{w}}_{c}^{(k) T}, \ddot{\boldsymbol{m}}_{c}^{(k) T}\right)_{1 \times 4 M}
\end{aligned}
$$

$(30 \cdot a \sim d)$

となる. また, $\boldsymbol{\alpha}_{c}{ }^{(k)}, \boldsymbol{\alpha}_{e}{ }^{(k)}$ は, 行列 $\boldsymbol{A}$ と $\boldsymbol{B}$ の成分で 構成される, それぞれ $4 M \times 4 M, 4 M \times 8$ 次の行列で あり, $\beta_{c}{ }^{(k)}$ は $4 M \times 4 M$ 次の次式で与えられる対角 行列である.

$$
\beta_{c}^{(k)}=\operatorname{diag}\ulcorner\underbrace{1,1, \cdots, 1}_{3 M}, \underbrace{0,0, \cdots, 0}_{M}\lrcorner
$$

全要素に対する $4 M N$ 個の条件は, 式（29）を用い $\tau$,

$$
\boldsymbol{\alpha}_{c} \boldsymbol{\partial}_{c}+\boldsymbol{\alpha}_{e} \boldsymbol{\partial}_{e}=-\boldsymbol{p}_{c}+\boldsymbol{\beta}_{c} \ddot{\boldsymbol{d}}_{c}
$$

とマトリックス方程式にまとめられる.ここに,

$$
\begin{aligned}
& \boldsymbol{a}_{c}=\Gamma \boldsymbol{a}_{c}^{(1)}, \boldsymbol{\alpha}_{c}^{(2)}, \cdots, \boldsymbol{\alpha}_{c}^{(N)}{ }_{\lrcorner 4 M N \times 4 M N} \\
& \left.\boldsymbol{\alpha}_{e}=\Gamma \boldsymbol{\alpha}_{e}^{(1)}, \boldsymbol{\alpha}_{e}^{(2)}, \cdots, \boldsymbol{\alpha}_{e}^{(N)}\right\lrcorner 4 M N \times 8 N \\
& \left.\beta_{c}=\Gamma \beta_{c}^{(1)}, \beta_{c}^{(2)}, \cdots, \beta_{c}^{(N)}\right\rfloor_{4 M N \times 4 M N} \\
& \boldsymbol{\delta}_{c}{ }^{T}=\left(\boldsymbol{\partial}_{c}{ }^{(1)} T, \boldsymbol{\partial}_{c}^{(2)} T, \cdots, \boldsymbol{\partial}_{c}^{(N) T}\right)_{1 \times 4 M N} \\
& \boldsymbol{\delta}_{e}{ }^{T}=\left(\boldsymbol{\delta}_{e}^{(1) T}, \boldsymbol{\delta}_{e}^{(2) T}, \cdots, \boldsymbol{\delta}_{e}^{(N) T}\right)_{1 \times 8 N} \\
& \boldsymbol{p}_{c}{ }^{T}=\left(\boldsymbol{p}_{c}^{(1) T}, \boldsymbol{p}_{c}^{(2) T}, \cdots, \boldsymbol{p}_{c}^{(N) T}\right)_{1 \times 4 M N} \\
& \ddot{\boldsymbol{\delta}}_{c}{ }^{T}=\left(\ddot{\boldsymbol{\partial}}_{c}^{(1) T}, \ddot{\boldsymbol{\partial}}_{c}^{(2) T}, \cdots, \ddot{\boldsymbol{\delta}}_{c}^{(N) T}\right)_{1 \times 4 M N}
\end{aligned}
$$

であり, 記号「 $\boldsymbol{X}^{(i)} 」(i=1 \sim N)$ は行列 $\boldsymbol{X}$ が対角行列 的に構成されることを意味する.

\section{（2）８個の条件}

（1）要素の境界点 1 および $(N)$ 要素の 境界点 $N+1$ でそれぞれ 4 つの境界条件が規定される. いま, 各点で 規定される条件の 1 つが次のように与えられたとする. 
$\left.\begin{array}{l}\text { 点 } 1 \quad\left(\xi=\xi_{0}\right) \text { で } M_{x}^{(1)}=0 \\ \text { 点 } N+1 \quad\left(\xi=\xi_{M+1}\right) \text { で } \Phi_{x}^{(N)}=0\end{array}\right\}$

$\cdot(34 \cdot a, b)$

上式の Fourier 係数は,

$$
m_{x}{ }^{(1)}\left(\xi_{0}\right)=0
$$

そして, 式 $(13 \cdot \mathrm{d}),(23 \cdot \mathbf{a})$ より次のように表わされる.

$$
\begin{aligned}
b_{17}(N) & \left(\xi_{M+1}\right) u^{(N)}\left(\xi_{M+1}\right) \\
& +\sum_{j=1}^{M+2} b_{18}{ }^{(N)}\left(\xi_{M+1}\right) A_{M+2}, w^{(N)}\left(\xi_{j-1}\right)=0
\end{aligned}
$$

他に規定される条件（ここでは斉次境界条件として扱 う）も式 (35) に類似な形で表わされる.さて, 境界点 で成立する条件を, 内部選点と端点に関する部分に分離 し, 行列表示すると次のようになる.

$$
\left.\begin{array}{l}
\boldsymbol{\gamma}_{c, 1}{ }^{(1)} \boldsymbol{\delta}_{c}^{(1)}+\boldsymbol{\gamma}_{e, 1}{ }^{(1)} \boldsymbol{\delta}_{e}{ }^{(1)}=\mathbf{0} \\
\boldsymbol{\gamma}_{c, N+1}{ }^{(N)} \boldsymbol{\delta}_{c}{ }^{(N)}+\boldsymbol{\gamma}_{e, N+1}{ }^{(N)} \boldsymbol{\delta}_{e}{ }^{(N)}=\mathbf{0}
\end{array}\right\}
$$

ここに, $\gamma_{c, 1}{ }^{(1)}$ と $\gamma_{c, N+1}{ }^{(N)}$ は $4 \times 4 M$ 次の行列, $\gamma_{e, 1}{ }^{(1)}$ と $\gamma_{e, N+1}{ }^{(N)}$ は $4 \times 8$ 次の行列であり, 下つき添字, $i$ （i=1,N+1） は境界点 $i$ を表わす.

\section{（3） 8(N-1) 個の条件}

この条件は分割点 $i(i=2 \sim N)$ で成立する 接続条件 で与えられる.分割点で成立する条件は次のようである.

$$
\left.\begin{array}{l}
U^{(i-1)}=U^{(i)}, V^{(i-1)}=V^{(i)} \\
W^{(i-1)}=W^{(i)}, \Phi_{x}^{(i-1)}=\Phi_{x}{ }^{(i)} \\
N_{x}^{(i-1)}=N_{x}^{(i)}, M_{x}{ }^{(i-1)}=M_{x}{ }^{(i)} \\
S_{x \theta}{ }^{(i-1)}=S_{x \theta}{ }^{(i)}, T_{x}^{(i-1)}=T_{x}^{(i)}
\end{array}\right\}
$$

ここに, $i=2 \sim N$ であり, 添字 $(i-1)$ の諸量は $\xi=$ $\xi_{M+1}$ を, 添字 (i) の諸量は $\xi=\xi_{0}$ をとる.

式 (37) の条件は, 式 (35) と同様な形で表わされる. 一例として式 $(37 \cdot a),(37 \cdot d)$ を示すと次のようである.

$$
\left.\begin{array}{c}
u^{(i-1)}\left(\xi_{M+1}\right)-u^{(i)}\left(\xi_{0}\right)=0 \\
b_{17}^{(i-1)}\left(\xi_{M+1}\right) u^{(i-1)}\left(\xi_{M+1}\right)-b_{17}{ }^{(i)}\left(\xi_{0}\right) u^{(i)}\left(\xi_{0}\right) \\
+\sum_{j=1}^{M+2}\left\{b_{18}{ }^{(i-1)}\left(\xi_{M+1}\right) A_{M+2, j} w^{(i-1)}\left(\xi_{j-1}\right)\right. \\
\left.-b_{18}{ }^{(i)}\left(\xi_{0}\right) A_{1, j} w^{(i)}\left(\xi_{j-1}\right)\right\}=0
\end{array}\right\}
$$

さて, 式 (37) の条件を, 式 (36) に習い行列表示す ると，

$$
\begin{aligned}
& \boldsymbol{\gamma}_{c, i^{(i-1)}} \boldsymbol{\delta}_{c}{ }^{(i-1)}+\gamma_{e, i^{(i-1)}} \boldsymbol{\delta}_{e}^{(i-1)}+\gamma_{c, i}{ }^{(i)} \boldsymbol{\delta}_{c}{ }^{(i)} \\
& +\left\{\gamma_{e, i^{(i)}}\right\} \boldsymbol{\delta}_{e}{ }^{(i)}=0 \quad(i=2 \sim N) \cdots \cdots \cdots \cdots \cdots
\end{aligned}
$$

となる.ここに， $\gamma_{c}^{()}$および $\gamma_{e}^{()}$は，それぞれ $8 \times 4$ $M$ 次, $8 \times 8$ 次の行列であり, 下付き添字 $i$ は分割点 $i$ を意味する.

以上により，4(M+2)N本の方程式が得られ，それ らは時刻 $\tau$ における内部選点と端点での関数值で表わ
された. 後の数値計算の便宜上，(4) で整理しておく.

\section{(4) $4(M+2) N$ 本の方程式}

式（36）および式（39）は1つの方程式にまとめられ る.

$$
\boldsymbol{\gamma}_{c} \boldsymbol{\delta}_{c}+\boldsymbol{\gamma}_{e} \boldsymbol{\delta}_{e}=\mathbf{0}
$$

ここに， $\gamma_{c}$ および $\gamma_{e}$ はそれぞれ $8 N \times 4 M N$ 次, $8 N$ $\times 8 N$ 次の行列で, 次に示すようにサブマトリックスか ら組み立てられる。

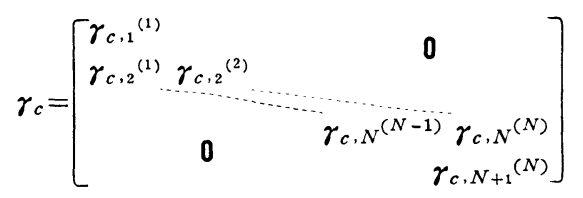

一方， $\gamma_{e}$ は上式で添字 $c$ を $e$ に置き換えたものであ る.

さて, 式 (32) と式 (40) を結合すると, 時刻てにお けるマトリックス方程式は次のように表わされる.

$$
\left[\begin{array}{c:c}
\boldsymbol{\alpha}_{c} & \boldsymbol{\alpha}_{e} \\
\hdashline \boldsymbol{\gamma}_{c} & \boldsymbol{\gamma}_{e}
\end{array}\right]\left\{\begin{array}{c}
\boldsymbol{\delta}_{c} \\
\hdashline \boldsymbol{\delta}_{e}
\end{array}\right\}=-\left\{\begin{array}{c}
\boldsymbol{p}_{c} \\
\hdashline \mathbf{0}
\end{array}\right\}+\left[\begin{array}{c:c}
\boldsymbol{\beta}_{c} & \mathbf{0} \\
\hdashline \mathbf{0} & \mathbf{0}
\end{array}\right]\left\{\begin{array}{c}
\ddot{\boldsymbol{\delta}}_{c} \\
\hdashline \mathbf{0}
\end{array}\right\}
$$

もし, 行列 $\gamma_{e}$ が非特異なら注 3), 式 (42) の下半分 は次のように再整理される.

$$
\boldsymbol{\delta}_{e}=-\boldsymbol{r}_{e}{ }^{-1} \boldsymbol{\gamma}_{c} \boldsymbol{\delta}_{c}
$$

式（43）を式 (42) の上半分に代入すれば, 次のマトリ ックス方程式が得られる.

$$
\boldsymbol{\alpha} \boldsymbol{\delta}_{c}=-\boldsymbol{p}_{c}+\boldsymbol{\beta}_{c} \ddot{\boldsymbol{z}}_{c}
$$

ここに, $4 M N \times 4 M N$ 次の行列 $\boldsymbol{\alpha}$ 沈次式で与えられる.

$$
\boldsymbol{\alpha}=\boldsymbol{\alpha}_{c}-\boldsymbol{\alpha}_{e} \boldsymbol{\gamma}_{e}^{-1} \boldsymbol{\gamma}_{c}
$$

式 (42)，(44）は，(2) の境界条件が 斉次型で規定さ れた場合であるが，もし非斉次ならば一部次のように変 更される. すなわち, あらかじめ規定された力学量（た とえば, 変位, 応力など) の值をべクトル $\boldsymbol{f}$ (ベクトル $\boldsymbol{\delta}_{\boldsymbol{e}}$ の大きさと一致させるため $8 N \times 1$ 次とする）と記 せば, 式 (42) の右辺第 1 項の零ベクトルが $\boldsymbol{f}$ に, 式 (44)の $\boldsymbol{p}_{c}$ が $\boldsymbol{p}_{c}-\boldsymbol{\alpha}_{e} \boldsymbol{\gamma}_{e}^{-1} \boldsymbol{f}$ となる.

以上で, 式 (42), (44) の時間に関する方程式が得ら れ, 空間領域の近似は完成した. あとは与えられた初期 条件のもとに, 解けばよいことになる. なお, 静的問題 では式 (42),(44) の時間微分の項を零とすればよい.

\section{5. 数值計算例}

いままでに述べた手法の適用可能性を数值例でもって

注 3）たとえば，5．の軸対称荷重を受ける球款の問題では, 行列 $\gamma_{e}$ が特異となる. このときは, 式 (42) により解析を行わ なければならない. 
示す．（1）では空間の離散化について論じ，(2)では （1）の成果を踏まえて空間を近似し，既往の時間積分ス キームを用いて動的応答解析を行う。なお，数值例には 基本的な形状の円筒款と球款を選んだ.

\section{(1) 静 的 問 題}

a） 液圧を受ける円筒款

1 要素当たりの選点数 $M$ を決めるため, Fig. 3 に 示す液圧（軸対称荷重, 波数 $n=0$ ）を受ける円筒殼を 要素数 $N=1$ (要素分割が行われていない) で解析する. Fig. 3 亿選点数 $M=7,8,9,10,11$ に対する变位 $W$ と曲げモーメント $M_{x}$ を, 理論值 ${ }^{14)}$ との比較で示す. いずれの選点数によっても，本計算值は理論值とよく一 致している. なお, 参考のために Fig. 4 に選点の配置 状況を示す. 図が示すように, 選点は端点の近くに密に 分布している. このような分布は, 次の数值例も示すよ うに, 境界近傍の応力集中に対する追従性を高为る働き をしているように思われる。

以後の計算はすべて $M=11$ を用いることにする.も ちろん, 荷重状態や殼の形状によっては, これが不十分 な場合もあると思われるが, そのときは要素分割数 $N$ を 増すことで対処できる。

b）一様な外圧を受ける球壳

本手法の变数係数の微分方程式一の適用性および境界 近傍の応力集中に対する追従性を調べるため, Fig. 5 に示す軸対称荷重（波数 $n=0$ ）を受ける球殸を扱う. なお，本手法をこの球款に適用する場合，頂点で成立す

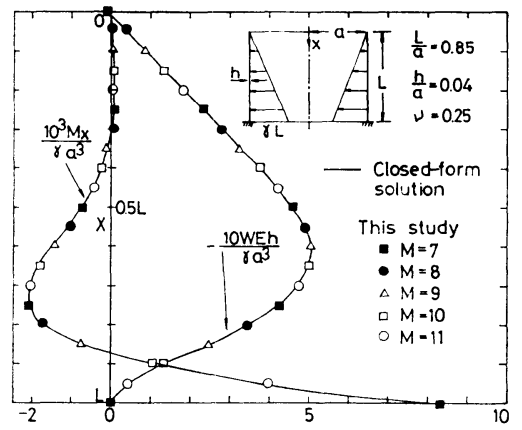

Fig. 3 Normal displacement and meridional bending moment for cylindrical shell under liquid pressure.

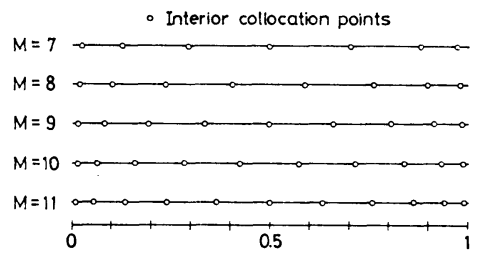

Fig. 4 Location of interior collocation points.

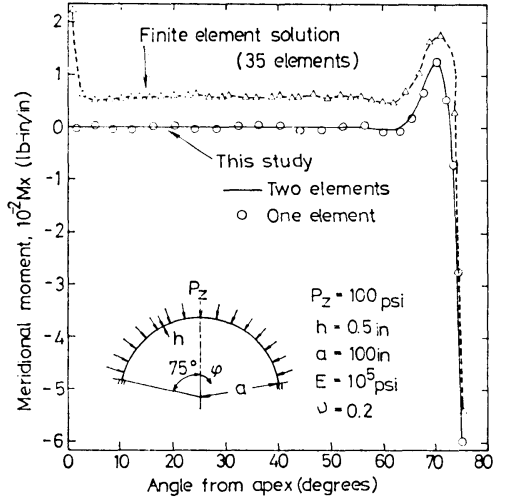

Fig. 5 Meridional bending moment for spherical cap under uniform pressure $(1$ in. $=2.54 \mathrm{~cm}$, $1 \mathrm{psi}=6.9 \mathrm{kN} / \mathrm{m}^{2}, 1 \mathrm{lb}-\mathrm{in} .=0.113 \mathrm{~N}-\mathrm{m}$ ).

る条件 ${ }^{15)}$ を一端における境界条件とし， $0^{\circ} \leq \varphi \leq 75^{\circ}(\varphi$ =経角）の範囲で解析をする.

この数值例の荷重状態の場合には，固定端近傍を除い ては膜応力状態が成立し, 曲げ応力の存在しない領域を 生じるのが普通である. Fig. 5 に, 要素数 $N=1,2$ (等 分割）に対する曲げモーメント $M_{x}$ を示す. $N=1$ で は，固定端から離れた領域においては波を打つ現象がみ られるものの, 固定端近傍の急激な変化は十分にとらえ ている.一方 $N=2$ では, 波を打つ現象もなく, ほぼ完 全に膜応力状態が達成されている．図には参考のため に, FEM (円錐台要素) による結果 ${ }^{21}$ も示したが，全 領域に曲げ応力が発生している. なお，曲線要素による 場合には, 上記の欠点は改善される ${ }^{16)}$.

c）風荷重を受ける円筒殼

b) で示したように，解の精度は要素分割によって改 善された.さらに,この点を確認するため, 風荷重を受 ける片持円筒殸を解析する.ただし, 既往の理論值 ${ }^{17)}$ （Donnell 理論による）と比較するため, Donnell 理論 に基づく微分方程式を用いて計算を行った，風荷重は高 さ方向には一定とし, 周方向の分布（波数 $n=0,1, \cdots$, 6）は次式を用いた

$$
P_{z}=\sigma \sum_{n=0}^{6} p_{z}{ }^{(n)} \cos n \theta=\sigma(-0.387+0.338 \cos \theta
$$

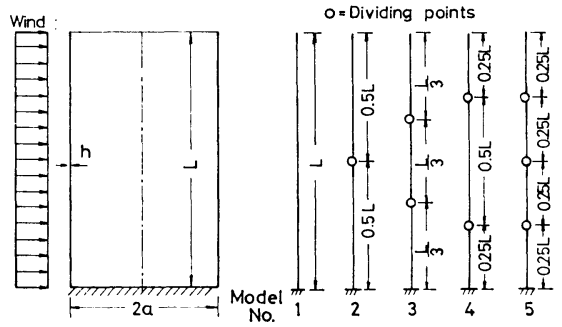

Fig. 6 Cylindrical shell under wind loading and division into elements along meridional coordinate. 


$$
\begin{aligned}
& +0.533 \cos 2 \theta+0.471 \cos 3 \theta \\
& +0.166 \cos 4 \theta-0.066 \cos 5 \theta \\
& -0.055 \cos 6 \theta) \quad \ldots \ldots \ldots \ldots \ldots \ldots \ldots \ldots \ldots
\end{aligned}
$$

計算は Fig. 6 に示す要素分割, 1 要素 (Model No. 1, 以下 No. 1 と記す), 2 要素 (No. 2), 3 要素 (No. $3 ， 4$ ) および 4 要素 (No. 5) に対して行った. 款の諸 元は, $L / a=3, h / a=0.005, \nu=0.3$ である.

結果 ( $W, N_{x}, M_{x}$ および $\left.T_{x}\right)$ をシェル理論值の比 較で Table 1 に示す. 1 要素 (No. 1) の結果に着目す れば, 変位 $W$ と合応力 $N_{\boldsymbol{x}}$ は十分な精度で求まってい るが，曲げモーメント $M_{x}$ および等価せん断力 $T_{x}$ は かなりの誤差が生じていることがわかる. しかし, 要素 分割数 $N$ を増せば, $M_{x}$ と $T_{x}$ は変位と同程度の精度 で求まっている. 特に, No. $4(N=3$, 境界近傍を細分 割) と No. 5 ( $N=4$, 等分割) の結果は全領域で精度の

\begin{tabular}{|c|c|c|c|c|c|c|}
\hline \multirow{2}{*}{$\begin{array}{c}\text { Height } \\
\text { above base }\end{array}$} & \multirow{2}{*}{ Exact } & \multicolumn{5}{|c|}{ Model No. } \\
\hline & & 1 & 2 & 3 & 4 & 5 \\
\hline \multicolumn{7}{|c|}{ (a) Normal displacement. $W E h / \sigma a^{2}$} \\
\hline $0.00 \mathrm{~L}$ & 0.0 & 0.0 & 0.0 & 0.0 & 0.0 & 0.0 \\
\hline $0.05 L$ & 19.845 & 18.437 & 20.191 & 19.853 & 19.859 & 19.859 \\
\hline $0.10 \mathrm{~L}$ & 33.354 & 35.285 & 32.968 & 33.329 & 33.354 & 33.354 \\
\hline $0.40 \mathrm{~L}$ & 188.369 & 187.339 & 188.502 & 188.369 & 188.367 & 188.369 \\
\hline $0.50 \mathrm{~L}$ & 258.999 & 258.386 & 259.033 & 258.999 & 258.999 & 258.999 \\
\hline $0.70 \mathrm{~L}$ & 413.152 & 412.263 & 413.218 & 413.185 & 413.175 & 413.181 \\
\hline $0.90 \mathrm{~L}$ & 572.152 & 571.495 & 572.232 & 572.136 & 572.180 & 572.153 \\
\hline $1.00 \mathrm{~L}$ & 652.576 & 652.211 & 652.571 & 652.579 & 652.514 & 652.576 \\
\hline \multicolumn{7}{|c|}{ (b) Meridional stress resultant, $N_{x} / \sigma a$} \\
\hline $0.00 L$ & 31.972 & 31.953 & 31.974 & 31.971 & 31.972 & 31.972 \\
\hline $0.05 L$ & 29.079 & 28.903 & 29.109 & 29.085 & 29.080 & 29.080 \\
\hline $0.10 L$ & 26.165 & 26.236 & 26.123 & 26.166 & 26.163 & 26.163 \\
\hline $0.40 \mathrm{~L}$ & 11.730 & 11.950 & 11.689 & 11.730 & 11.730 & 11.730 \\
\hline $0.50 L$ & 8.143 & 7.849 & 8.142 & 8.143 & 8.143 & 8.143 \\
\hline $0.70 \mathrm{~L}$ & 2.917 & 2.932 & 2.918 & 2.916 & 2.917 & 2.917 \\
\hline $0.90 L$ & 0.326 & 0.325 & 0.325 & 0.326 & 0.326 & 0.326 \\
\hline $1.00 \mathrm{~L}$ & 0.0 & 0.0 & 0.0 & 0.0 & 0.0 & 0.0 \\
\hline
\end{tabular}

Table 1 Results for cylindrical shell under wind loading by using different types of division.

(c) Meridional bending moment, $M_{x} / \sigma a^{2}$

\begin{tabular}{l|r|r|r|r|r|r}
\hline $0.00 \mathrm{~L}$ & -0.0200 & -0.0241 & -0.0200 & -0.0200 & -0.0200 & -0.0200 \\
$0.05 \mathrm{~L}$ & 0.0012 & 0.0027 & 0.0017 & 0.0011 & 0.0012 & 0.0012 \\
$0.10 \mathrm{~L}$ & -0.0038 & -0.0004 & -0.0003 & -0.0025 & -0.0039 & -0.0039 \\
$0.40 \mathrm{~L}$ & 0.0007 & 0.0022 & 0.0007 & 0.0007 & 0.0007 & 0.0007 \\
$0.50 \mathrm{~L}$ & 0.0011 & 0.0012 & 0.0011 & 0.0011 & 0.0011 & 0.0011 \\
$0.70 \mathrm{~L}$ & 0.0021 & 0.0035 & 0.0022 & 0.0021 & 0.0021 & 0.0021 \\
$0.90 \mathrm{~L}$ & 0.0032 & 0.0042 & 0.0031 & 0.0032 & 0.0032 & 0.0032 \\
$1.00 \mathrm{~L}$ & 0.0 & 0.0 & 0.0 & 0.0 & 0.0 & 0.0 \\
\hline \multicolumn{7}{c}{ (d) } \\
\hline $0.00 \mathrm{~L}$ & -0.6470 & -0.8292 & -0.6386 & -0.6467 & -0.6470 & -0.6470 \\
$0.05 \mathrm{~L}$ & 0.0335 & 0.0760 & 0.0356 & 0.0370 & 0.0334 & 0.0334 \\
$0.10 \mathrm{~L}$ & -0.0040 & -0.0132 & -0.0076 & -0.0044 & -0.0038 & -0.0038 \\
$0.40 \mathrm{~L}$ & -0.0070 & -0.0180 & -0.0074 & -0.0070 & -0.0070 & -0.0070 \\
$0.50 \mathrm{~L}$ & -0.0081 & -0.0065 & -0.0080 & -0.0081 & -0.0081 & -0.0081 \\
$0.70 \mathrm{~L}$ & -0.0091 & -0.0082 & -0.0099 & -0.0082 & -0.0091 & -0.0091 \\
$0.90 \mathrm{~L}$ & -0.0095 & -0.0141 & -0.0086 & -0.0095 & -0.0095 & -0.0095 \\
$1.00 \mathrm{~L}$ & 0.0 & 0.0 & 0.0 & 0.0 & 0.0 & 0.0 \\
\hline
\end{tabular}

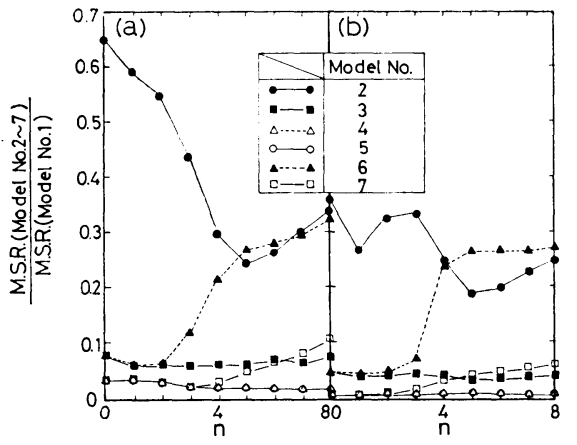

Fig. 7 Mean square residuals of (a) Eq. $11 \cdot a$; (b) Eq. $11 \cdot c$.

よい解が得られた.この点も含めて, 以下に要素分割数 および分割パターンの解の精度に及ぼす影響を, 平均二 乗残差 (M.S.R.) の面から検討する.

M.S.R. は次式で求められる.

$$
\text { M.S.R. }=\left[\sum_{i=1}^{N} l_{i} \int_{0}^{1} R_{i}{ }^{2}(\xi) d \xi\right]^{1 / 2}
$$

ここに， $l_{i}$ および $R_{i}$ は，それぞれ (i) 要素 の経線の長さおよび残差である．計算は前述の 分割パターンに, 新たに No. $6(N=2$, 固定端 より $1: 2$ で分割) と No. $7(N=3,1: 1: 2$ で分割）を加え, 式 (46) の $p_{z}{ }^{(n)}$ を 1 と置き, 波数 $n=0,1, \cdots, 8$ に対して行った.

Fig. 7 には, Donnell 理論に基づく式 (11・ a), (11·c) の M.S.R. を示す. 図の縦軸は No. $2 \sim 7$ と No. 1 の残差の比である. 図より次の 点がわかる. (1) 分割数の増加および境界近傍 の細分割は M.S.R. を減少させる. (2) M.S.R. は波数 $n$ にも依存し, 一般には $n$ の増加ととも に大きくなる傾向がある. なお， 7 つの分割方 法のうち, No. 4 のが適切と思われる.この分 割パターンの M.S.R. は, No. 5 のそれとほぼ 同じ值をとり, かつ $n$ に依存しないものとなっ ている. この点は, 先程の Table 1 の結果に も反映されている.
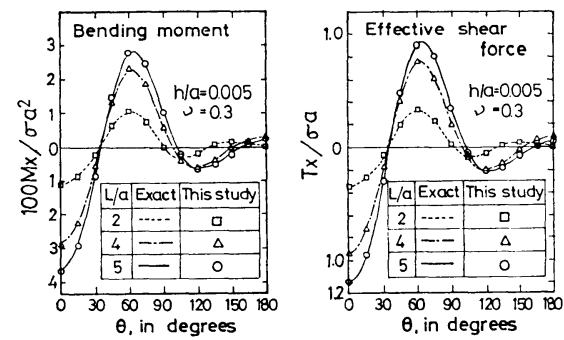

Fig. 8 Meridional bending moment and effective shear force at clamped end. 

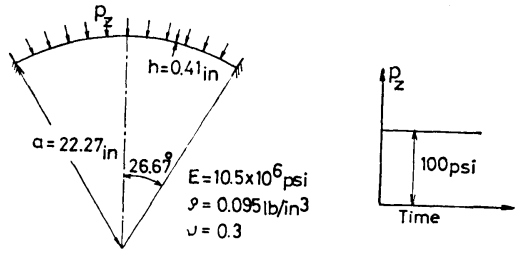

Fig. 9 Spherical cap under pulse loading ( 1 in. $=$ $\left.2.54 \mathrm{~cm}, 1 \mathrm{psi}=6.9 \mathrm{kN} / \mathrm{m}^{2}, 1 \mathrm{lb} / \mathrm{in}^{8}=0.272 \mathrm{~N} / \mathrm{m}^{3}\right)$.

Fig. 8 には, 高さと半径の比 $L / a=2,4,5$ に対して 計算した 前述の 風荷重（式 (46)）による固定端の $M_{x}$ と $T_{x}$ の周方向分布を示す. $L / a$ によらず理論值とよ く一致している. 要素分割数は 3 である。

本計算值は要素分割数, 要素分割パターンおよび一要 素内の選点数の影響を受けるが，平均二乗残差を空間領 域に対する離散化の程度の判定に用いて, 残差の大きい 要素の細分割あるいは一要素内の選点数を増すなどして 解析すれば，本計算值はより 信頼性の高いものとなろ う.

\section{（2）動 的 問 題}

a) 衝撃荷重を受ける球殼

モデルは Klein ら ${ }^{18)}$ が空間に対して FEM (42 要素の 円錐台要素，約 130 自由度）を用いて解析した, Fig. 9 に示す衝撃荷重（波数 $n=0$ ）を受ける球殼である. 本 法は 2 要素 (等分割, 約 70 自由度) で空間を近似し, 数值積分法は文献 18）と同じく, Chan ら ${ }^{19)}$ のキーム により解析した.

Fig. 10 に頂点のたわみ $W$ と固定端の合応力 $N_{x}$ の 時間応答を示す. 時間刻み幅 $\Delta T$ は, Klein らと同様 な $\Delta T=0.1 \times 10^{-4} \mathrm{~s}\left(=T_{0} / 54, T_{0}\right.$ は 1 次固有周期 $)$ と，

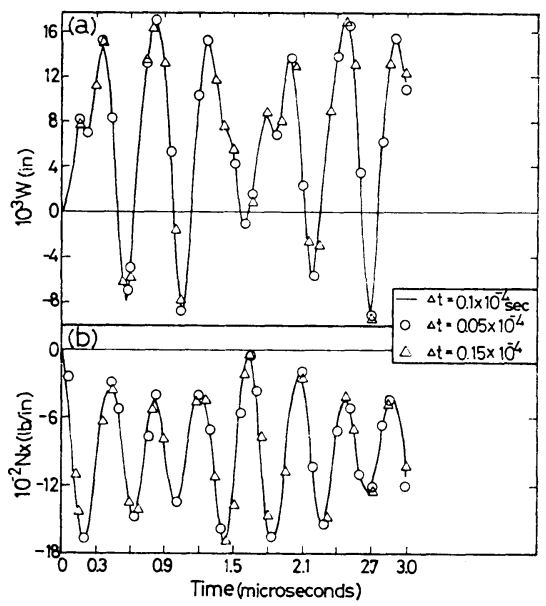

Fig. 10 Dynamic responses of spherical cap; (a) normal displacement at apex $(1 \mathrm{in} .=2.54$ cm); (b) meridional stress resultant at clamped end $(1 \mathrm{lb} / \mathrm{in} .=1.752 \mathrm{~N} / \mathrm{cm})$.
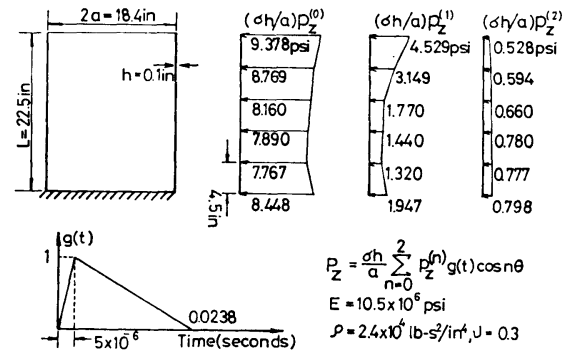

Fig. 11 Cylindrical shell under blast loading $\left(1 \mathrm{in} .=2.54 \mathrm{~cm}, 1 \mathrm{psi}=6.9 \mathrm{kN} / \mathrm{m}^{2}, 1 \mathrm{lb}-\mathrm{s}^{2} /\right.$ in. $\left.{ }^{4}=0.107 \mathrm{~N}-\mathrm{s}^{2} / \mathrm{cm}^{4}\right)$.

応答に与える影響を調べるために, $\Delta T=0.15 \times 10^{-4} \mathrm{~s}$ $\left(T_{0} / 36\right), 0.05 \times 10^{-4} \mathrm{~s}\left(T_{0} / 108\right)$ とした. 図が示すよう に，いずれの $\Delta T$ によっても時間応答には有意な変化 は認められない，なお， $\mathrm{FEM}^{18)}$ との直接的な比較は示 さないが，時間応答はよく一致した。

b） 衝撃荷重を受ける円筒殼

モデルは Johnson ら ${ }^{3)}$ が空間に対して FDM を適用 した片持円筒款である. 荷重は周方向に $n=0,1,2$ の 分布をし，その時間および壳の高さ方向の分布を Fig. 11 に示す。時間積分アルゴリズムは文献 3) と同じく Houbolt 法 ${ }^{20)}$ を用い，時間刻み幅は $\Delta T=5 \times 10^{-4} \mathrm{~s}$ と した.

自由端のたわみ $W$ と固定端の曲げモーメント $M_{x}$ の時間履歷を FDM との比較で Fig. 12 に示す. 結果 はどれもよい一致を示しており，本法によっても十分に 時間応答の追跡が可能である．なお，空間の近似は，本 法は 3 要素分割で, FDM は曲げモーメントの収束性か ら差分点数 140 とした. ちなみに，本法の末知数の数

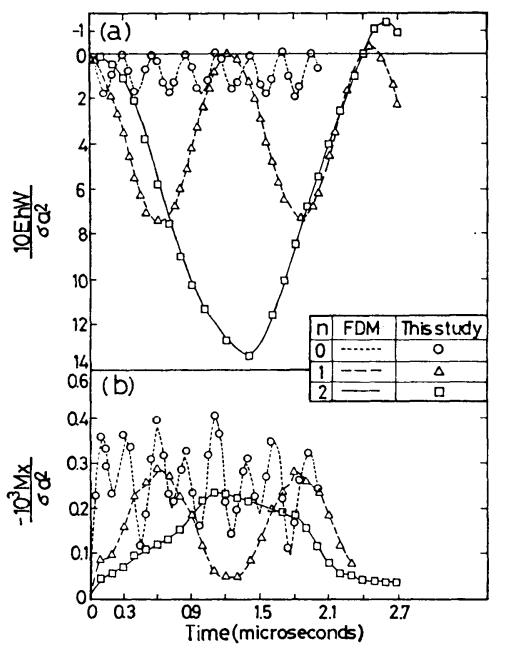

Fig. 12 Dynamic responses of cylindrical shell; (a) normal displacement at free end; (b) meridional bending moment at clamped end. 
は FDM のそれに比べ, $1 / 4$ 程度に減少している.最後 に計算時間について述べる. 本法の波数 $n=0,1,2$ に 対する計算時間は約 130 秒であった. この時間は差分 法のそれの $1 / 3$ 程度に短縮 されている. 使用機種は北 海道大学大型計算機センターの HITAC M-200 H であ る.

（1），(2）の数值例は限られた形状の凯, 荷重条件およ び境界条件に対してなされたが，それらを通じて手法の 妥当性と有用性はだいたい確認できたものと思われる.

\section{6. おわりに}

回転殸の静的問題および動的応答問題に対して, 選点 法による空間領域の離散化を試み, その有効性の検討を 行った. 定式化においては, 離散化後の連立方程式およ び時間に関する連立常微分方程式の係数行列が, システ マチックに求められるように配慮された.

本手法による数值結果は, 静的問題のみならず動的問 題に対してもほぼ満足のいくものであり, 本手法の妥当 性が検証できた.さらに, 空間の離散化の近似度の判定 の目安として, 平均二乗残差を解析に併用するならば, 本手法の結果はより高精度なものになることを数值例に より示した.このことは, 本手法が, 特徵である簡便性 を生かした効率のよい実用的解析法として, さらに発展 が可能であることを示唆しているものと思われる.

最後に, 本研究を遂行するにあたりご指導を賜わった 北海道大学工学部 芳村 仁教授に深く感謝いたします.

\section{付 録 I}

係数 $a_{1} \sim a_{36}$ および $b_{1} \sim b_{18}$ は, 次のようになる.

$$
\begin{aligned}
a_{1}= & b / s^{2}, a_{2}=r a_{1} \\
a_{3}= & -b\left(\nu r_{1} r_{2}+r^{2} / s^{2}+\nu_{4} n^{2} / 2 r\right)-k r_{1}^{2}\left(r^{2} / s^{2}\right. \\
& \left.+n^{2} / \nu_{1} r^{2}\right) \\
a_{4}= & n\left(1 / 2+k r_{1} r_{2}\right) / \nu_{1} s r \\
a_{5}= & -r n\left(b \nu_{6} / 2+k r_{1} r_{2} \nu_{2} / \nu_{1}\right) / s r \\
a_{6}= & -b\left(r_{1}+\nu r_{2}\right) / s-k r_{1}\left(r^{2} / s^{2}+n^{2} / \nu_{1} r^{2}\right) / s \\
a_{7}= & -b\left\{r_{1}^{\prime}+r\left(r_{1}-r_{2}\right)\right\} / s+k r n^{2} r_{1} \nu_{2} / \nu_{1} s r^{2} \\
a_{8}= & -r_{1} / s, a_{9}=-\nu_{4} r r_{1} / s, a_{10}=-a_{4} \\
a_{11}= & -n\left\{b r \nu_{6} / 2+k\left(r_{1}^{\prime} r_{2}+r r_{1} r_{2} \nu_{2}\right) / \nu_{1}\right\} / s r \\
a_{12}= & \left(1 / 2+k r_{2}^{2}\right) / \nu_{1} s^{2} \\
a_{13}= & r\left(1 / 2+k r_{1} r_{2}\right) / \nu_{1} s^{2} \\
a_{14}= & -n^{2}\left(b+k r_{2}^{2}\right) / r^{2}+\left(r_{1} r_{2}-r^{2} / s^{2}\right) / 2 \nu_{1} \\
& -k r_{1} r_{2}\left(r^{2} / s^{2}-r_{2}^{2}\right) / \nu_{1} \\
a_{15}= & -k n r_{2} / \nu_{1} r s^{2}, a_{16}=\nu_{1} r a_{15} \\
a_{17}= & b n\left(\nu r_{1}+r_{2}\right) / r-k n r_{2}\left(r_{1} r_{2} / \nu_{1}-n^{2} / r^{2}\right) / r
\end{aligned}
$$

$$
\begin{aligned}
& a_{18}=-2 n r_{2} / r \\
& a_{19}=b\left(r_{1}+\nu r_{2}\right) / s+k r_{1}\left(\gamma^{2} / s^{3}+2 n^{2} / s \nu_{1} r^{2}\right) \\
& a_{20}=b r\left(r_{1}+\nu r_{2}\right) / s+k r_{1}{ }^{\prime}\left(r^{2} / s^{3}+2 n^{2} / s \nu_{1} r^{2}\right) \\
& -k r r_{1}\left(2 r_{1} r_{2}+r^{2} / s^{2}-n^{2} / r^{2}\right) / s \\
& a_{21}=2 a_{15}, a_{22}=k n r\left(\nu_{3} r_{2}-2 r_{1}\right) / \nu_{1} s^{2} r \\
& a_{23}=b n\left(\nu r_{1}+r_{2}\right) / r+k n^{3} r_{2} / r^{3} \\
& +k n\left\{r^{2}\left(\nu_{3} r_{1}-2 \nu_{2} r_{2}\right) / s^{2}-r_{1} r_{2}{ }^{2} \nu_{3}\right\} / \nu_{1} r \\
& a_{24}=k\left(\gamma^{2} / s^{2}+2 n^{2} / \nu_{1} r^{2}\right) / s^{2} \\
& a_{25}=-k r\left(2 n^{2} / \nu_{1} r^{2}+2 r_{1} r_{2}-r^{2} / s^{2}\right) / s^{2} \\
& a_{26}=-b\left(r_{1}{ }^{2}+r_{2}{ }^{2}+2 \nu r_{1} r_{2}\right)-k n^{4} / r^{4} \\
& +k n^{2}\left(\nu_{3} r_{1} r_{2}+2 r^{2} \nu_{2} / s^{2}\right) / \nu_{1} r^{2} \\
& a_{27}=1 / s^{2}, a_{28}=r \nu_{5} / s^{2} \\
& a_{29}=-\nu n^{2} / r^{2}-\nu_{4} r_{1} r_{2}, a_{30}=b k r_{1} / s \\
& a_{31}=b k\left(r_{1}{ }^{\prime}+\nu r r_{1}\right) / s, a_{32}=b k n \nu r_{2} / r \\
& a_{33}=b k / s^{2}, a_{34}=r \nu a_{33} \\
& a_{35}=-b k \nu n^{2} / r^{2}, a_{36}=1 \\
& b_{1}=b / s, b_{2}=b r \nu / s \\
& b_{3}=b n \nu / r, b_{4}=-b\left(r_{1}+\nu r_{2}\right) \\
& b_{5}=-n\left(1+2 k r_{1} r_{2}\right) / 2 \nu_{1} r \\
& b_{6}=\left(1+2 r_{2}^{2}\right) / 2 \nu_{1} s, b_{7}=-r b_{6} \\
& b_{8}=-k n r_{2} / s \nu_{1} r, \quad b_{9}=k n \gamma r_{2} / s \nu_{1} \\
& b_{10}=k r_{1}\left(r^{2} / s^{2}+2 n^{2} / \nu_{1} r^{2}\right) \\
& b_{11}=-2 k n r_{2} / s \nu_{1} r, \quad b_{12}=r \nu_{3} b_{11} / 2 \\
& b_{13}=k\left(r^{2} / s^{3}+2 n^{2} / s \nu_{1} r^{2}\right) \\
& b_{14}=-k \nu_{3} r n^{2} / s \nu_{1} r^{2}, b_{15}=1 / s \\
& b_{16}=r \nu_{4} / s, b_{17}=r_{1}, b_{18}=b_{15} \\
& b=1 /\left(1-\nu^{2}\right), k=(h / a)^{2} / 12 \\
& \nu_{1}=1+\nu, \nu_{2}=2+\nu, \nu_{3}=3+\nu \text {, } \\
& \nu_{4}=1-\nu, \nu_{5}=2-\nu, \nu_{6}=3-\nu
\end{aligned}
$$$$
\text { ここに, }
$$

\section{参 考 文 献}

1）䉆津久一郎ほか共編：有限要素法ハンドブック I 基礎編, 培風館, 1981 .

2) Budiansky, B. and P.P. Radkowski : Numerical Analysis of Unsymmetrical Bending of Shells of Revolution, AIAA J, Vol. 1, No. 8, pp. 1833 1842, 1963.

3) Johnson, D.E. and R. Greif : Dynamic Response of a Cylindrical Shell ; Two Numerical Methods, AIAA J, Vol. 4, No. 3, pp. 486 494, 1966.

4) Smith, T.A. : Explicit High-Order Finite-Difference Analysis of Rotationallyj Symmetric Shells, AIAA J, Vol. 18, No. 3, pp. 309 317, 1980.

5）三上 隆・芳村 仁: 選点法による回転殸の固有振動数 の解析, 土木学会論文報告集, 第 335 号, pp. 69 78, 1983.

6) . Langhaar, H.L. et al. : Stability of Hyperboloidal Cooling Tower, Proc. of ASCE, Vol. 96, No. EM 5, pp. 753 779, 1970.

7) Stoneking, J.E. and A.P. Boresi : A Theory for Free Vibration of Orthotropic Shells of Revolution, Nucl. Engng and Des., Vol. 14, pp. 271 285, 1970. 
8) Langhaar, H.L. and S.C. Chu : Piecewise Polynomials and the Partition Method for Ordinary Differential Equations, Development in Theoretical and Applied Mechanics, Vol. 8, Pergamon Press, pp. 553 564, 1970.

9) Sharma, S.K. and A.P. Boresi : Finite Element Weighted Residual Methods; Axisymmetric Shells, Proc. of ASCE, Vol. 104, No. EM 4, pp. 895 909, 1978.

10) Novozhilov, V.V. : The Theory of Thin Shells, P. Noordhoff, 1959.

11) Finlayson, B.A. : The Method Weighted Residual and Variational Principles, Academic Press, 1972.

12) Prenter, P.M. : Splines and Variational Methods, John Wiley \& Son, 1975.

13) Abramowitz, M. and I.A. Stegun (Eds.) : Handbook of Mathematical Functions, Dover Publications, 1970.

14) Timoshenko, S.P. and S. Woinowski-Krieger : Theory of Plates and Shells, 2nd ed., McGraw-Hill, 1959.

15) Greebaum, K. : Comments "Numerical Analysis of Unsymmetrical Bending of Shells of Revolution", AIAA J, Vol. 2, No. 3, pp. 590 591, 1964.

16）川股重也：コンピュータによる 構造工学構座, シェル構
造解析, 培風館. 1974 .

17) Gopalacharyulu, S. and D.J. Johns : Cantilever Cylindrical Shells under Assumed Wind Pressures, Proc. of ASCE, Vol. 99, No. EM 5, pp. 943 956, 1973.

18) Klein, S. and R.J. Sylvester : The Linear Dynamic Analysis of Shells of Revolution by the Matrix Displacement Method, Proceedings of the 1st Conference on Matrix Methods in Structural Mechanics, AFFDLTR-66-80, Wright Patterson AFB, Ohio, Oct., pp. 299 328, 1965.

19) Chan, S.P. et al. : Transient Analysis of Forced Vibrations of Complex Structural-Mechanical Systems, J.R. Aeronaut. Soc., Vol. 66, pp. 457 460, 1962.

20) Houbolt, J.C. : A Recurrence Matrix Solution for the Dynamic Response of Elastic Aircraft, J. Aeronaut. Sci., Vol. 17, pp. 540 550, 1950.

21) Stricklin, J.A. et al. : Improvements on the Analysis of Shells of Revolution by the Matrix Displacement Method, AIAA J., Vol. 4, No. 11, pp. 2069 2072, 1966.

(1983.4.4 ·受付) 